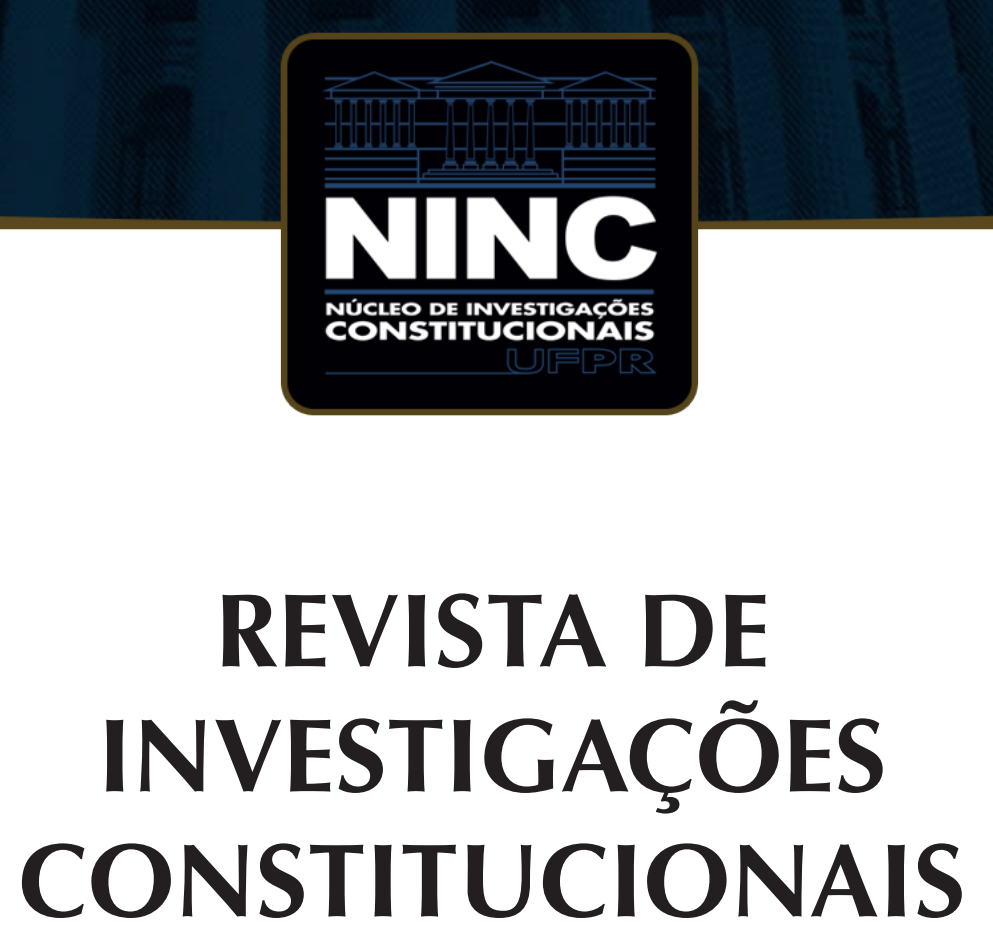

JOURNAL OF CONSTITUTIONAL RESEARCH

vol. 5 | n. 1 | janeiro/abril 2018 | ISSN 2359-5639 | Periodicidade quadrimestral Curitiba | Núcleo de Investigações Constitucionais da UFPR | www.ninc.com.br 


\title{
Um diálogo sobre a autonomia da Constituição e os direitos humanos: aproximações hermenêuticas à noção de bloco de constitucionalidade
}

\section{A dialogue between the autonomy of the Constitution and human rights: hermeneutical approaches on the notion of constitutionality block}

\author{
RAFAEL FONSECA FERREIRA* \\ Universidade Federal do Rio Grande (Brasil) \\ rafaelferreira@furg.br
}

TÊMIS LIMBERGER**

Universidade do Vale do Rio dos Sinos (Brasil) temis@viars.net

Recebido/Received: 28.03.2017 / March 28th, 2017 Aprovado/Approved: 16.11.2017 / November 16th, 2017

\section{Resumo}

Uma exploração das possibilidades hermenêuticas da Constituição reivindica uma análise crítica do seu atua modo de compreensão. A partir de uma análise dialógico-hermenêutica se objetiva criticar o modo reducionista (e positivista) de compreender a Constituição que obstrui seu caráter constitutivo e paradigmático em seu compromisso com os direitos humanos e fundamentais. Nesse cenário, sendo os direitos humanos o elo material entre a Constituição e o direito internacional, abre-se o caminho para se pensar o processo de

\section{Abstract}

An exploration of the hermeneutic possibilities of the Constitution claims a critical analysis of its present mode of comprehension. From a dialogic-hermeneutic analysis, the objective is to criticize the reductionist mode (and positivist) of comprehending the Constitution that obstructs its constitutive and paradigmatic character in the commitment to human and fundamental rights. In this scenario, human rights being the material link between the Constitution and international law, opens the way to think about the process of internationalization of the Constitution, which has

Como citar esse artigo/How to cite this article: FERREIRA, Rafael Fonseca; LIMBERGER, Têmis Um diálogo sobre a autonomia da constituição e os direitos humanos: aproximações hermenêuticas a noção de bloco de constitucionalidade. Revista de Investigações Constitucionais, Curitiba, vol. 5, n. 1, p. 317-330, jan./abr. 2018. DOI: 10.5380/rinc.v5i1.51457.

* Professor da Graduação e do Programa de Pós-Graduação em Direito da Universidade Federal do Rio Grande (Rio Grande, RS, Brasil). Doutor, mestre e pós-doutorando em Direito pela Universidade do Vale do Rio dos Sinos (São Leopoldo, RS, Brasil). Advogado. E-mail: rafaelferreira@furg.br.

** Professora da Graduação e do Programa de Pós-Graduação em Direito da Universidade do Vale do Rio dos Sinos (São Leopoldo, RS, Brasil). Doutora pela Universidade Pompeu Fabra de Barcelona (Barcelona, Espanha). Pós-doutora pela Universidade de Sevilha (Sevilha, Espanha). Mestra pela Universidade Federal do Rio Grande do Sul (Porto Alegre, RS, Brasil). Procuradora de Justiça-MP/RS. E-mail: temis@viars.net. 
internacionalização da Constituição, que tem o desafio de romper com o imaginário jurídico dominante. Finalmente, desse diálogo hermenêutico surge o espaço para o desenvolvimento de um bloco de constitucionalidade em direitos humanos no constitucionalismo brasileiro.

Palavras-chave: hermenêutica; Constituição; internacionalização; direitos humanos; bloco de constitucionalidade. the challenge of breaking the dominant legal imaginary. Finally, from this hermeneutic dialogue arises the space for the development of a constitutional block in human rights in Brazilian constitutionalism.

Keywords: hermeneutics; Constitution; internationalization; human rights; constitutional block.

\section{SUMÁRIO}

1. Introdução; 2. A "inefetividade" da Constituição como discurso casuístico: uma crítica hermenêutica em benefício dos direitos humanos e do acontecer produtivo da Constituição; 3. O bloco de constitucionalidade e a internacionalização da Constituição: uma saída hermenêutica para a vinculatividade normativa dos direitos humanos; 4. Considerações finais; 5 . Referências.

\section{INTRODUÇÃO}

Em tempos difíceis de Constituição e de (des)respeito ao seu núcleo de direitos humanos (e fundamentais) no Brasil, o tema dos tratados internacionais de direitos humanos poderia trilhar novos horizontes se ao invés de discutirmos o status normativo (formal) dos tratados, passássemos a considerar o caráter ontológico dos direitos humanos para o constitucionalismo do segundo pós-guerra e disso consolidarmos uma jurisdição constitucional mais identificada com as promessas da modernidade. Nesse contexto, a busca por novos horizontes vem no sentido de recuperar o caráter normativo e constitutivo dos direitos humanos a partir de uma adequada compreensão do papel hermenêutico da própria Constituição no Brasil. Usando a abordagem dialógico hermenêutica de Gadamer e a dinâmica pró-vocativa da pergunta1 procurar-se-á auferir uma nova dimensão conteudística sobre o tema, na medida em que a pergunta, enquanto start de qualquer reflexão hermenêutica, tem a finalidade de romper ou estranhar as camadas de sentido que, algumas vezes, encobrem o verdadeiro ser de um ente 2 .

Então, se a premissa de que a Constituição Federal de 1988 inaugurou um novo paradigma normativo ao instituir o Estado Democrático de Direito, consagrando como seu núcleo a prevalência dos direitos humanos e a defesa dos direitos fundamentais, devemos discutir as razões das sistemáticas, e diversas delas recentes, violações democráticas e atentatórias a esse núcleo constitucional e fundante. Observem que durante o ano de 2016, vários fatos podem servir para demonstrar o quanto os direitos

\footnotetext{
1 GADAMER, Hans-Georg. Verdade e método I: traços fundamentais de uma hermenêutica filosófica. 12. ed. Petrópolis: Vozes; Bragança Paulista: EDUSF, 2012. p. 487-489.

2 Cf. STRECK, Lenio Luiz. Diferença (ontológica) entre texto e norma: afastando o fantasma do relativismo. Revista da Faculdade de Direito da Universidade de Lisboa, Lisboa, v. 46, n. 1, jul. 2006. p. 62.
} 
humanos, fundamentais e sociais, deixaram de ser prioridade frente aos discursos pragmáticos e eficientistas da política, da economia e do próprio direito3.

Não é o propósito discutir esses fatos em si, senão apenas usá-los como argumentação discursiva. O texto apenas pretende se colocar como "pró-vocação", isto é, chamar o outro a sua vocação humana de interpretar e refletir ${ }^{4}$ sobre as possibilidades hermenêuticas e do necessário caráter de resistência da Constituição frente aos cenários de dificuldades, considerando o seu compromisso com os direitos humanos e a justificação do seu elo material mais objetivo, os tratados internacionais de direitos humanos. E a partir disso desmitificar a problemática, de caráter positivista-normativista, que gira em torno do imaginário jurídico dominante de que a simples definição do status formal dos tratados pudesse ter resolvido a questão interpretativa dos direitos humanos.

A tarefa hermenêutica (filosófica), aqui trazida como crítica, é então colocar em jogo, para além do reducionismo do estabelecimento do status formal dos tratados internacionais de direitos humanos, outras possibilidades conteudísticas para a Constituição e os direitos humanos e fundamentais no desenvolvimento da tese do bloco de constitucionalidade como incremento hermenêutico, democrático e de resistência contra a predação do núcleo essencial da Constituição. Por consequência, demonstrar a partir desse recorte que a "inefetividade" da Constituição é um discurso, no mais das vezes, retórico e predatório da autonomia constitucional.

\section{A "INEFETIVIDADE" DA CONSTITUIÇÃO COMO DISCURSO CA- SUÍSTICO: UMA CRÍTICA HERMENÊUTICA EM BENEFÍCIO DOS DIREITOS HUMANOS E DO ACONTECER PRODUTIVO DA CONS- TITUIÇÃO}

A Constituição brasileira de 1988 embora tenha representado um marco de conquista pública e democrática, aparentemente não repercutiu todo o potencial transformador da realidade de grande parcela de brasileiros se considerarmos, em particular, o resgate dos compromissos de justiça social colocados como objetivo fundamental daquela nova República. Também, não conseguiu motivar a comunidade política e

\footnotetext{
3 Observem, por exemplo: a decisão do STF no HC 126.292 e, depois, nas ADC's 43 e 44 relativizando a garantia da presunção de inocência; em Brasília, um juiz da vara da infância e juventude autorizou a utilização de métodos de tortura para expulsar adolescentes de uma escola (TJDFT, Vara da Infância e da Juventude do DF, proc. n. 2016.01.3.011286-6); em caráter dito como "Medida excepcional" da Justiça se autorizou a polícia a fazer buscas e apreensões coletivas em favela no Rio de Janeiro contra expresso texto legal e constitucional (TJRJ, 2a. Vara Criminal (Jac), proc. n. 0397891-81.2016.8.19.0001); uma chacina de 111 presos feita pela polícia é "legítima defesa" para parte do Tribunal de Justiça de São Paulo (TJSP, 4a. Câmara Criminal, apelações n. 0338975-60.1996.8.26.0001 e 0007473-49.2014. 8.26.0001).

4 GALÁN, Pedro Cerezo. Reivindicación del diálogo. Madri: Real Academia de Ciencias Morales y Políticas, 1997. p. 121.
} 
jurídica para o necessário rompimento com a herança patrimonialista-estamentista daqueles que se julgavam - e ainda se julgam - os donos do Estado e do poder5.

Portanto, a inefetividade da Constituição, enquanto discurso casuístico, não passa, no mais das vezes, de tentativa de enfraquecimento dos compromissos prometidos (e não cumpridos) para vulnerabilização dos textos através de emendas e reformas e até mesmo de discursos de nova Constituição. No entanto, num ambiente de pragmatismo jurídico e político quaisquer dessas ideias representam a fragilização do Estado Democrático de Direito naquilo que ele tem de mais caro - a realização da justiça social - em benefício de minorias de poder e/ou correntes ideológicas dominantes.

A comunidade jurídica que poderia/deveria exercer um papel de vanguarda na defesa e mesmo na construção de uma identidade constitucional adequada a realidade brasileira, parece ser incapaz de construir uma teoria da Constituição identificada com a história e as promessas da modernidade6. Aliás, o próprio modo de operação mecanicista do Direito tem colocado a sociedade em dificuldades e a Constituição à disposição dos predadores de sua resistência.

De certa maneira, a incompreensão hermenêutica da Constituição também se projeta como o principal fator da intensa judicialização da política, corroborada, por certo, pela ampliação do catálogo de direitos fundamentais. Contudo, é a ineficiência (insuficiência e deficiência) política e as dificuldades cívico-democráticas de reconhecimento que motivam a pulverização de ações judicias sobre questões que, a priori, deveriam ser apenas produto da tensão democrática entre o poder político e a pressão social, mas que sistematicamente têm sido delegadas ao Poder Judiciário. Daí porque vivemos as voltas com o debate político do não preenchimento do espaço público democrático e os desencantamentos das teses voluntaristas e ativistas na interpretação do direito.

Portanto, em face de uma "baixa constitucionalidade", o sentido do "ser do ente Estado Democrático de Direito" e suas possibilidades de realização da função social do Direito estão mal compreendidas, de modo que os textos jurídicos e as ações políticas não encontram ressonância da validade constitucional. Há, enfim, um abismo entre o modo-de fazer Direito e a concepção de Estado Democrático de Direito7

(Re)encontrar um ambiente de resistência constitucional ao pragmatismo político e jurídico em tempos difíceis de interpretação no/do Direito é um desafio hermenêutico. A resistência aqui deve ser entendida como a força normativa, autonomia do Direito, frente a situações de crise $^{8}$.

\footnotetext{
5 Nesse sentido ver FAORO, R. Os donos do poder: formação do patronato político brasileiro. São Paulo: Biblioteca Azul, 2012.

6 Cf. STRECK, Lenio Luiz. Jurisdição Constitucional e Decisão Jurídica. 3. ed. São Paulo: Editora Revista dos Tribunais, 2013. p. 138-139.

7 STRECK, Lenio Luiz. Jurisdição Constitucional e Decisão Jurídica. 3. ed. São Paulo: Editora Revista dos Tribunais, 2013. p. 73.

8 Cf. HESSE, Konrad. Escritos de derecho constitucional (Selección). Colección Estudios Constitucionales. Madrid: Centro de
} 
Com efeito, buscar horizontes ontológicos para uma noção fundacional (identitária) de Constituição não deve apenas se restringir a questões epistemológico-dogmáticas, mas assentar um novo cenário compromissado com a democracia, a cidadania, os objetivos fundamentais da República e a justiça social. Todavia, isso passa por um melhor estreitamento hermenêutico da dialética entre Direitos Humanos, Estado de Direito e Constituição, pois é a partir disso que se vai lograr a superação da ideia estritamente ética dos direitos humanos à sua elevação a caráter jurídico e político legitimador dos Estados de Direito e de suas Constituições, inclusive, para se constituir uma esfera capaz de repassar o arbítrio da jurisdição interna de cada Estado?.

En suma, el constitucionalismo, en el momento en el que supera y trasciende los límites señalados por el positivismo jurídico, no puede correr el riesgo de mantenerse en el vacío. En definitiva, si hay una constante en la historia del constitucionalismo, es precisamente esa doble vocación de la que hemos partido: la de resistir, para consolidar o mantener esferas de autonomía, derechos e identidades distintas, pero también la de participar, para contribuir a determinar los rasgos de una pertenencia común, de una común existencia política ${ }^{10}$

Diante disso, no recorte proposto, o desafio da pergunta constitucionalmente adequada em sede de direitos humanos no Brasil, tem em sua gênese uma crítica ao positivismo-normativista quanto ao isolamento das fontes de direito internacional e a hierarquização da relação entre das ordens jurídicas interna e internacional. Atualmente, as fronteiras entre o direito constitucional e o direito internacional são estreitas e apontam para uma progressiva constitucionalização do direito internacional, revelando uma dialética com o conteúdo de mesma natureza advindo das organizações internacionais, pactos e convenções de direitos humanos ${ }^{11}$.

Isso quer dizer que a autonomia da Constituição, enquanto pacto fundante, não está a serviço da soberania e dos interesses casuísticos, mas voltada para o cumprimento das promessas de uma sociedade justa e solidária orientada para e pelos direitos humanos e fundamentais, não podendo encontrar resistência na conservação de inautênticas premissas de conhecimento. Arejar a Constituição com o direito internacional não é medida de conveniência, mas necessidade imperiosa do próprio texto e tônica

Estudios Constitucionales, 1983. p. 27-28.

9 PÉREZ LUÑO, A. E. Derechos humanos, estado de derecho y constituición. 10. ed. Madrid: Tecnos, 2010. p. 131.

10 FIORAVANTI, Maurizio. Constitucionalismo: experiencias históricas y tendencias actuales. Trad. Adela Mora Cañada y Manuel Martínez Neira. Madrid: Editorial Trotta, 2014. p. 13

11 CANOTILHO, J. J. Gomes. "Brancosos" e a interconstitucionalidade: itinerários dos discursos sobre a historicidade constitucional. 2. ed. Lisboa: Almedina, 2008. p. 285. 
do constitucionalismo contemporâneo, ou continuaremos assentindo os direitos humanos (e seus tratados) em papel secundário, à disposição das conveniências dos discursos políticos e jurídicos dominantes. No entanto, isso é jogar a sociedade no século XIX e a abstrair a identificação do movimento constitucional pós-Segunda Guerra com os direitos humanos, sobretudo, num país de modernidade tardia como é o Brasil. Isto é, um país que não obstante uma Constituição compromissória e dirigente e a promessa de uma espécie de Estado Social e Democrático, ainda não conseguiu implementar as condições para vencer as desigualdades sociais, os contrastes e as misérias ${ }^{12}$.

Essas são questões precisam estar implicadas em qualquer processo interpretativo de regras e princípios, antecipadas a qualquer tentativa metodológica formal ou procedimental de seu uso instrumental. Assim, numa dinâmica hermenêutica, a Constituição, constitui o modo-de-ser de uma sociedade e de um Estado e, por isso, não está à disposição. A Constituição hermeneuticamente deve traduzir um presente que não esquece o passado e que mira o futuro, inaugura novos tempos, sem perder a história, a qual deve ser trazida no contexto de qualquer interpretação, é o compromisso da comunidade com a tradição.

Portanto, é preciso recobrar uma adequada noção de legitimidade aplicativa da Constituição que possa encontrar um fundamento ancorado em preceitos autênticos de nossa sociedade ou mesmo que possa fazer jus a "constituição cidadã", hoje a serviço de diversas retóricas instrumentais ou de (des)ilusões moralistas e populistas. Não se nega os avanços, porém não se pode apostar num modelo de altos e baixos que tem no positivismo, o qual ainda aposta na relação sujeito-objeto, o protagonista das dificuldades compreensivas sobre os compromissos da materialidade constitucional.

O desafio é romper com o imaginário de uma compreensão normativa e metodologizada da Constituição, para um diálogo hermenêutico (compartilhado e democrático, porque intersubjetivo) que dê conta das duas dimensões constitutivas fundamentais, a compreensão que se antecipa na experiência de mundo do intérprete e o sentido do texto que se fundem numa totalidade. O não-dito sustenta, por causa da pré-compreensão, tudo aquilo que aparece na palavra do discurso. Há sempre um acontecer que opera quando falamos e que sustenta o sentido profundo das realidades jurídicas expressas nos códigos e na Constituição ${ }^{13}$. Aliás, essa antecipação de sentido que é sonegada pelas metodologias tradicionais de conhecimento - típicas do positivismo - quando buscam uma pretensão neutralidade dedutiva e fática de interpretar, reduzindo a compreensão ao universo dos textos, dos códigos e da Constituição higienizados de toda a realidade social.

\footnotetext{
12 STRECK, Lenio Luiz. Jurisdição Constitucional e Decisão Jurídica. 3. ed. São Paulo: Editora Revista dos Tribunais, 2013. p. 141.

13 STEIN, Ernildo. Apresentação. In: STRECK, Lenio Luiz. Jurisdição Constitucional e Decisão Jurídica. 3. ed. São Paulo: Editora Revista dos Tribunais, 2013. p. 14-15.
} 
No fundo, trata-se de uma busca pelo desvelamento acerca do não dito sobre Constituição ou mesmo daquilo que Susanna Pozzolo indica existir por trás do termo "Constituição", de que não se resume a norma jurídica fundamental que reúne os princípios essenciais em que se funda cada nação e suas instituições básicas, mas que conta com um significado prévio a positivação ${ }^{14}$.

Nisso o diálogo hermenêutico é determinante. A pergunta provocadora da reflexão, para além das respostas causais e operacionais, como por exemplo, definir o status normativo formal dos tratados internacionais de direitos humanos (dito), ofuscando outras possibilidades de efetivação e tratamento democrático dos direitos humanos, interpela as condições de possibilidade (não-dito), isto é, no caso, a lógica procedimental verificativa do status hierárquico-normativista dos instrumentos internacionais ${ }^{15}$. Isso porque, é no não-dito, que se escondem os discursos que trazem a presença linear da herança positivista de matriz kelseniana (normativista) orientada pela onipresença do Estado (nacional) como única fonte racional de onde ele emana e, contextualmente, onde o direito internacional dos direitos humanos, nunca poderá ser considerado vinculante ${ }^{16}$.

Por isso, a desconstrução do discurso do imaginário jurídico dominante no Brasil e que obscurece a materialização constitucional, passa pela transformação no tratamento das fontes jurídicas e o modo de compreender os influxos históricos do movimento constitucional pós-Segunda Guerra, onde ganham espaço os tratados internacionais de direitos humanos em face de um pluralismo normativo que tem na Constituição as condições materiais de possibilidade ${ }^{17}$.

\section{O BLOCO DE CONSTITUCIONALIDADE E A INTERNACIONALIZA- ÇÃO DA CONSTITUIÇÃO: UMA SAÍDA HERMENÊUTICA PARA A VINCULATIVIDADE NORMATIVA DOS DIREITOS HUMANOS}

O movimento de internacionalização do Direito ${ }^{18}$ (e da Constituição) ${ }^{19}$ consubstanciado no aprimoramento das possibilidades de alinhamento político, econômico e

\footnotetext{
14 POZZOLO, S. Neocostituzionalismo e positivismo giuridico. Torino: Giappichelli Editori, 2001. p. 20 et seq.

15 A desconstrução do paradigma hierárquico-normativo dominante (doutrinário e jurisprudencial no STF) sobre o tema ver em: FERREIRA, Rafael F. Internacionalização da Constituição: Diálogo hermenêutico, perguntas adequadas e bloco de constitucionalidade. Rio de Janeiro: Editora Lumen Juris, 2016. p. 29-132.

16 Não se pode deixar de consignar que o próprio monismo kelseniano sempre foi dependente da ideia de escalonamento, já que somente se afirmaria como possível em razão da ausência de positividade do direito internacional. Cf. KELSEN, Hans. Teoria pura do direito. Trad. João Baptista Machado. 8. ed. São Paulo: Editora WMF Martins Fontes, 2009. p. 46; 348; Teoria geral do direito e do estado. Trad. Luís Carlos Borges. 4. ed. São Paulo: Martins Fontes, 2005. p. 488.

17 Cf. FERREIRA, Rafael F. Internacionalização da Constituição: Diálogo hermenêutico, perguntas adequadas e bloco de constitucionalidade. Rio de Janeiro: Editora Lumen Juris, 2016. p. 305.

18 SALDANHA, Jânia Maria. Lopes Novas geometrias e novos sentidos: Internacionalização do Direito e internacionalização do diálogo dos sistemas de justiça. In: Constituição, sistemas sociais e hermenêutica: anuário do programa de Pós-Graduação em Direito da UNISINOS: mestrado e doutorado STRECK, Lenio Luiz, ROCHA, Leonel Severo, ENGELMANN, Wilson. Porto Alegre, Livraria do Advogado Editora; São Leopoldo, UNISINOS, 2012. p. 137-160.
}

19 FERREIRA, Rafael F. Internacionalização da Constituição: Diálogo hermenêutico, perguntas adequadas e bloco de constitu- 
jurídico tem nos direitos humanos seu principal elo e legitimidade. Por certo, a ampliação dos canais de produção de conhecimento traz variáveis, por vezes, difíceis de serem administradas, mormente quando inadequadamente compreendidas ou importadas 20 . Mas, também, é certo que poderá proporcionar experiências ou "acquis constitucionais"21 que possam melhor vincular ações e políticas de justiça social e de resistência constitucional.

Todavia, do ponto de vista metodológico talvez se observe a maior dificuldade. Isso porque no Brasil a hierarquização das ordens interna-internacional tem sido o principal fundamento dos discursos de exceção aos direitos humanos nas práticas tribunalícias, problema conhecido efeito colateral do positivismo hierárquico-normativista. $\mathrm{O}$ Supremo Tribunal Federal, pós-constituição de 1988 notadamente, ainda que de forma involuntária, é o principal responsável pela profusão dessa postura, não obstante no tempo tenha transitado na defesa das teses da hierarquia legal, supralegal e constitucional dos tratados internacionais de direitos humanos22.

Portanto, essas dificuldades metodológicas (e de compreensão) são produto de um problema de paradigma, de positivismo. É como olhar o novo com os olhos do velho, como diz Streck ${ }^{23}$. Um olhar hermenêutico da Constituição terá Nela própria a resposta para a pergunta/pró-vocação sobre a insegurança da hierarquização formal das ordens interna-internacional, isto é, a chave para a estabilização dessa tensão normativa intersistemas. Por isso, qualificar a dimensão hermenêutica da Constituição é reconhecê-la como portadora de um núcleo de identidade aberto ao desenvolvimento e não uma pretensão de última resposta.

Daí porque, a necessária cooperatividade constitucional dos Estados está diretamente vinculada à abertura frente às possíveis vinculações internacionais de efeito imediato interno24, onde, uma possível saída para essa interpelação está qualificação e continuidade normativa da relação vinculativa da Constituição com o Direito Internacional e, no caso ora defendido, no desenvolvimento da tese do bloco de constitucionalidade.

O desenvolvimento hermenêutico de um bloco de constitucionalidade 25 para os tratados internacionais de direitos humanos adquire relevância na medida em que

cionalidade. Rio de Janeiro: Editora Lumen Juris, 2016.

20 STRECK, Lenio Luiz. As recepções teóricas inadequadas em terrae brasilis. In Revista de Direitos Fundamentais e Democracia, Curitiba, v. 10, n. 10, p. 2-37, jul./dez. 2011.

21 CANOTILHO, J. J. Gomes. "Brancosos” e a interconstitucionalidade: itinerários dos discursos sobre a historicidade constitucional. 2. ed. Lisboa: Almedina, 2008. p. 27.

22 Cf. FERREIRA, Rafael F. Internacionalização da Constituição: Diálogo hermenêutico, perguntas adequadas e bloco de constitucionalidade. Rio de Janeiro: Editora Lumen Juris, 2016. p. 49 et seq.

23 STRECK, Lenio Luiz. Jurisdição Constitucional e Decisão Jurídica. 3. ed. São Paulo: Editora Revista dos Tribunais, 2013. p. 42. 24 HÄBERLE, Peter. Pluralismo y constituición: estúdios de teoria constitucional de la sociedad aberta. Madrid: Tecnos, 2002. p. 294.

25 Sobre a origem da noção de bloco de constitucionalidade a partir da decisão do Conseil Constitutionnell (1971) ver FAVOREU, Louis; RUBIO LLORENTE, Francisco. El bloque de la constitucionalidad. 1. ed. Madrid: Civitas, 1991. p. 30. 
amplia os termos do debate constitucional modificando a ideia reducionista e formal de que as controvérsias constitucionais se resumem a "literalidade" de regras e princípios expressos no texto constitucional. É preciso dizer que o texto só o é em sua dimensão normativa e dentro de uma realidade e adaptação histórica, traço marcante e distintivo da hermenêutica em relação ao positivismo. Noutras palavras, o sentido material da ideia de Estado Constitucional enquanto "sociedade aberta", onde o sistema jurídico e seus postulados básicos exigem de seu intérprete uma atitude aberta fazendo da hermenêutica a instância histórico-crítica, estruturada em um processo dinâmico de experiências práticas em detrimento de um monopólio metodológico cerrado e hermético ${ }^{26}$.

Considerando o cenário de hierarquização formal de ordens e as dificuldades vinculativas dos direitos humanos, em particular, dos tratados internacionais de direitos humanos, o desenvolvimento hermenêutico de um bloco de constitucionalidade serviria para materializar o compromisso com os direitos humanos e ampliar o olhar da própria jurisdição constitucional. Não se trata, prima facie, de um busca pela ampliação de direito positivo ou positivação de direitos humanos, mas de dar sentido (hermenêutico) e fluxo aos $\S \S 1^{\circ}$. e $2^{\circ}$. do art. $5^{\circ}$. Constituição brasileira, num exercício de densificação teórico-interpretativa de resistência aos discursos dominantes que se valem dos formalismos reducionistas e das mecanicizações "interpretativas" para excetuar os direitos humanos não obstante toda a carga histórica e cultural do Brasil e da própria América Latina. Aliás, registra-se que essa foi, inclusive, a grande preocupação dos textos democráticos contemporâneos, que trouxeram em sua essência a necessidade de rompimento e a vedação de retrocesso àquelas práticas autoritárias através dos direitos humanos (e fundamentais). Logo, a sonegação dessas possibilidades de retrocesso (e de negação da história), talvez seja o maior efeito colateral das metodologias interpretativas tradicionais e do ranço formalista e conceitual do positivismo.

A interface internacional da Constituição brasileira por intermédio da dinâmica dos parágrafos originários do art. ${ }^{5027}$. mais do que permite, reivindica a construção hermenêutica do bloco de constitucionalidade, justamente para que o debate reducionista do status normativo dos tratados de direitos humanos não fique à mercê das conveniências políticas e jurídicas dos Estados frente aos compromissos internacionais de direitos humanos.

Por isso, diga-se que o desenvolvimento de um bloco de constitucionalidade "es compatible con la idea de constitución escrita y con la supremacía de la misma por

\footnotetext{
26 HÄBERLE, Peter. Pluralismo y constituición: estúdios de teoria constitucional de la sociedad aberta. Madrid: Tecnos, 2002. p. 45.

27 Conforme já destacado, a inserção do $\S 3^{\circ}$. no art. $5^{\circ}$. da $\mathrm{CF} / 88$, do ponto de vista hermenêutico, não solucionou o problema normativo material dos direitos humanos, apenas um problema formal (status hierárquico). Aliás, de duvidosa constitucionalidade, conforme explora FERREIRA, Rafael F. Internacionalização da Constituição: Diálogo hermenêutico, perguntas adequadas e bloco de constitucionalidade. Rio de Janeiro: Editora Lumen Juris, 2016. p. 288.
} 
cuanto es por mandato de la propia constitución que normas que no hacen parte de su articulado comparten empero su misma fuerza normativa"28. Mais ainda: dá sentido ao conjunto normativo que contém disposições, princípios e valores que representam a somatória daquilo que se adiciona à Constituição escrita, em função daquilo que nela é consagrado Bidart Campos ${ }^{29}$. Por isso, é que se pode dizer que o bloco de constitucionalidade, com a oxigenação do direito internacional dos direitos humanos, imprime vigor à força normativa da Constituição, servindo-Ihe de parâmetro hermenêutico de magnitude material.

Numa crítica, a noção de bloco de constitucionalidade é um chamamento a aparentemente esquecida dimensão interpretativa do Direito onde se buscar reconectar o elo dos direitos humanos (e sua integração pelos tratados) com a Constituição. O processo de comunicação entre a Constituição e o Direito Internacional tem nos direitos humanos o tema da aproximação, ou melhor, da adequada interpelação (pergunta) transformadora. Com razão, portanto, Arnaud quando afirma que os grandes problemas do momento passam a ser prioritariamente a transformação do modo de produção do direito, o modo de tratamento dos litígios e a proteção aos indivíduos assegurados até aqui pelo Estado -, mormente diante da notada tendência de internacionalização do Direito, em particular, das Constituições.

A principal conquista de um bloco de constitucionalidade é, além de uma contribuição material e vinculante para o tema, abrir o espaço para os novos horizontes do controle da constitucionalidade em matéria de direitos humanos, sufragando-se a estreiteza da concepção hierárquico-normativista das metodologias tradicionais e acreditando no desenvolvimento de práticas interpretativas nos limites materiais da Constituição. O caráter hermenêutico do bloco de constitucionalidade e sua relevância para a jurisdição constitucional agregam um novo vetor que surge na/da dimensão interpretativa da Constituição, a fim de dar vida a outros projetos de sentido para além da hierarquia formal e da soberania de ocasião.

A normatividade do texto constitucional não é estática, ela se constrói de forma produtiva enquanto modo de ser do próprio Direito e da sociedade e somente é capaz de se revelar interpretativamente na concretude individualizadora - applicatio30 -, uma das principais distinções críticas ao positivismo, que ainda acredita em respostas antes das perguntas e assujeitamento de sentidos. Portanto, a autonomia da Constituição não se exaure no texto, mas quando dele é capaz de se extrair as potencialidades

\footnotetext{
28 UPRIMNY YEPES, Rodrigo. Bloque de constitucionalidade, derechos humanos y processo penal. Colombia: Consejo Superior de la Judicatura, 2008. p. 32.

29 BIDART CAMPOS Gérman J. El derecho de la constitución y su fuerza normativa. Buenos Aires, Ediar, 1995. p. $264-269$.

30 Para Gadamer a aplicação, enquanto realização do compreender é individualizadora e não um ato de acoplamento a posteriori. Nesse complexo processo compreensivo o intérprete está sempre no entremeio do movimento de antecipação da pré-compreensão (círculo hermenêutico). GADAMER, Hans-Georg. Verdade e método I: traços fundamentais de uma hermenêutica filosófica. 12. ed. Petrópolis: Vozes; Bragança Paulista: EDUSF, 2012. p. 398-399.
} 
normativas em benefício da sociedade, materialização de seus princípios e objetivos fundamentais.

No caso, serve para apontar o fato de que a noção de bloco de constitucionalidade, na perspectiva dos direitos humanos, ilumina a pretensão de aprimoramento da ideia de normatividade e da fertilização da dimensão normativa da própria Constituição na direção dos tratados internacionais de direitos humanos. Uma vez que se o texto constitucional coloca-se como horizonte de possibilidades de sentido, as perguntas e respostas dialógicas acerca dos temas políticos, jurídicos e sociais em sede de direitos humanos - independentemente da fonte (p. ex.: tratados internacionais) - terão no e a partir do próprio texto a validação de qualquer verdade discursiva.

Na medida em que o bloco de constitucionalidade se coloca como resposta à pergunta da realidade (hierárquica) dos tratados internacionais de direitos humanos no Brasil. Então, se de um lado, é dever fundamental dos intérpretes alimentar a produção hermenêutica com a finalidade de consolidar a autonomia do texto constitucional, de outro, é também direito fundamental de uma sociedade a expressão de uma prestação jurisdicional constitucional identificada com a afirmação e evolução dos direitos humanos.

A pergunta hermenêutica como posta pelo texto rompe com o magma da discussão sobre a (in)definição do status normativo (hierárquico-normativo) para revelar a razão de ser histórica dos direitos humanos (e dos tratados) no constitucionalismo contemporâneo e, principalmente, a importância transformadora da realidade social dos textos das Constituições dos países de modernidade tardia como o Brasil, pois representam a garantia de rompimento com o autoritarismo de outros tempos, a vedação de retrocesso social, a realização de justiça social e a possibilidade da evolução democrática. Qualquer perspectiva discursiva que não tenha esse horizonte de sentido é porque observou a relação dialógica entre a Constituição e os direitos humanos, olvidando o impacto da mediação horizôntica fertilizado pelo influxo das experiências históricas e culturais que orientam a sedimentação democrática do constitucionalismo brasileiro ainda em evolução.

A paisagem complexa e plural do cenário político e a normatividade (internacionalizada) das Constituições democráticas de hoje orientadas para compromisso com os direitos humanos se colocarão como permanente pergunta em busca de novas respostas hermenêuticas ${ }^{31}$. Nesse contexto, a exploração hermenêutica de um bloco de constitucionalidade no paradigma hermenêutico atua como crítica ao positivismo e ao imaginário jurídico dominante. É, pois, no tensionamento e na realidade viva das Constituições que se dá o aprimoramento contínuo da normatividade constitucional e o asseguramento de sua autonomia para novos projetos de sentido do/no Direito.

31 FERREIRA, Rafael F. Internacionalização da Constituição: Diálogo hermenêutico, perguntas adequadas e bloco de constitucionalidade. Rio de Janeiro: Editora Lumen Juris, 2016. p. 322. 


\section{CONSIDERAÇÕES FINAIS}

A tarefa da hermenêutica (filosófica) é, enquanto crítica do imaginário dominante, desvelar o fenômeno para mostrá-lo como realmente ele é, isto é, identificar a partir de que momento essa verdade poderia ter se tornado inautêntica no horizonte do diálogo entre Constituição e o direito internacional dos direitos humanos nessa quadra da história. A dura realidade dos tratados internacionais de direitos humanos no Brasil, especialmente, pós-Constituição de 1988 somente ganhará novos horizontes quando se buscar desconstruir as premissas inadequadas que sustentam os discursos dominantes, como ora se pretendeu nesse texto.

Somente a consciência dos pressupostos que determinam a compreensão e que modelam nossos preconceitos é que faz permitir abrir-se para novas expectativas de sentido. Ou seja, somente tendo consciência de premissas paradigmáticas, no caso, do positivismo, para se poder desconstruir um imaginário. A partir disso é que se abrem novas expectativas de sentido, daí porque a hermenêutica é"a arte de poder não ter razão"32. Rever a questão dos tratados internacionais de direitos humanos sob uma nova realidade inaugurada pela ruptura constitucional de 1988, sobretudo, influenciada pelo movimento constitucional orientado pelo compromisso com os direitos humanos não poderia ser ancorada em premissas positivistas, eis a razão de que ainda estamos às voltas com a "inefetividade" da Constituição.

Na perspectiva do diálogo (hermenêutico) entre fontes (Constituição e tratados de direitos humanos) em detrimento do encobridor debate de cunho hierárquiconormativista, a 'ordem' formal desaparece na linguagem para desvelar a essência dessa nova dimensão da Constituição. De fato, embora se reconheça que o processo de comunicação entre a Constituição e o Direito Internacional tenha nos direitos humanos o canal de aproximação, somente o esforço dialógico-hermenêutico é capaz de favorecer a reflexão acerca do desenvolvimento de um bloco de constitucionalidade em sede de direitos humanos.

A produção de um espaço constitutivo reivindica ultrapassar as obviedades veladas nos discursos, essa é a grande contribuição da hermenêutica filosófica. Desvelar o óbvio para discutir a coisa partir daquilo que não foi problematizado pelo discurso jurídico tradicional (positivista) é dialogar/pró-vocar para mostrar o fenômeno como ele realmente é, é estar além do senso comum. Portanto, no recorte desenvolvido, as possiblidades hermenêuticas da internacionalização da Constituição passam pela adequada compreensão dos direitos humanos no horizonte do constitucionalismo contemporâneo e por uma visão de autonomia constitucional materialmente identificada com as promessas de justiça social de seus princípios e objetivos fundamentais.

32 MORATALLA, Agustin Domingo. El arte de poder no tener razón: la hermenéutica dialógica de H.G. Gadamer. Salamanca: Publicaciones Universidade Pontifica de Salamanca, 1991. 
Uma ideia de Constituição, do ponto de vista hermenêutico (filosófico), desafia uma complexidade crítica e histórico-fática que não se restringe ao velho olhar formal de superioridade hierárquico-normativa e de dependência do protagonismo de sujeitos que se acham donos dos sentidos da Constituição. De fato, a noção de Constituição não pode prescindir da política e do direito colocados de frente com a realidade social, sob pena de continuarmos a constituir um conceito sem coisa, isto é, uma Constituição que não constitui-a-ação, que é incapaz de oferecer resistência e despertar o sentimento de inclusão.

\section{REFERÊNCIAS}

BIDART CAMPOS Gérman J. El derecho de la constitución y su fuerza normativa. Buenos Aires: Ediar, 1995.

PÉREZ LUÑO, A. E. Derechos humanos, estado de derecho y constituición. 10. ed. Madrid: Tecnos, 2010.

CANOTILHO, J. J. Gomes. "Brancosos" e a interconstitucionalidade: itinerários dos discursos sobre a historicidade constitucional. 2. ed. Lisboa: Almedina, 2008.

FAORO, R. Os donos do poder: formação do patronato político brasileiro. São Paulo: Biblioteca Azul, 2012.

FAVOREU, Louis; RUBIO LLORENTE, Francisco. El bloque de la constitucionalidad. 1. ed. Madrid: Civitas, 1991.

FERREIRA, Rafael F. Internacionalização da Constituição: Diálogo hermenêutico, perguntas adequadas e bloco de constitucionalidade. Rio de Janeiro: Editora Lumen Juris, 2016.

FIORAVANTI, Maurizio. Constitucionalismo: experiencias históricas y tendencias actuales. Trad. Adela Mora Cañada y Manuel Martínez Neira. Madrid: Editorial Trotta, 2014.

GADAMER, Hans-Georg. Verdade e método I: traços fundamentais de uma hermenêutica filosófica. 12. ed. Petrópolis: Vozes; Bragança Paulista: EDUSF, 2012.

GALÁN, Pedro Cerezo. Reivindicación del diálogo. Madri: Real Academia de Ciencias Morales y Políticas, 1997.

HÄBERLE, Peter. Pluralismo y constituición: estúdios de teoria constitucional de la sociedad aberta. Madrid: Tecnos, 2002.

HESSE, Konrad. Escritos de derecho constitucional (Selección). Colección Estudios Constitucionales. Madrid: Centro de Estudios Constitucionales, 1983.

KELSEN, Hans. Teoria pura do direito. Trad. João Baptista Machado. 8. ed. São Paulo: Editora WMF Martins Fontes, 2009. 
KELSEN, Hans. Teoria geral do direito e do estado. Trad. Luís Carlos Borges. 4. ed. São Paulo: Martins Fontes, 2005.

MORATALLA, Agustin Domingo. El arte de poder no tener razón: la hermenéutica dialógica de H.G. Gadamer. Salamanca: Publicaciones Universidade Pontifica de Salamanca, 1991.

POZZOLO, S. Neocostituzionalismo e positivismo giuridico. Torino: Giappichelli Editori, 2001.

SALDANHA, Jânia Maria. Lopes Novas geometrias e novos sentidos: Internacionalização do Direito e internacionalização do diálogo dos sistemas de justiça. In: STRECK, Lenio Luiz, ROCHA, Leonel Severo, ENGELMANN, Wilson (Orgs.). Constituição, sistemas sociais e hermenêutica: anuário do programa de Pós-Graduação em Direito da UNISINOS: mestrado e doutorado. Porto Alegre: Livraria do Advogado Editora, 2012.

STEIN, Ernildo. Apresentação. In: STRECK, Lenio Luiz. Jurisdição Constitucional e Decisão Jurídica. 3. ed. São Paulo: Editora Revista dos Tribunais, 2013.

STRECK, Lenio Luiz. Jurisdição Constitucional e Decisão Jurídica. 3. ed. São Paulo: Editora Revista dos Tribunais, 2013.

STRECK, Lenio Luiz. Diferença (ontológica) entre texto e norma: afastando o fantasma do relativismo. Revista da Faculdade de Direito da Universidade de Lisboa, Lisboa, v. 46, n. 1, jul. 2006.

STRECK, Lenio Luiz. As recepções teóricas inadequadas em terrae brasilis. In Revista de Direitos Fundamentais e Democracia, Curitiba, v. 10, n. 10, p. 2-37, jul./dez. 2011.

UPRIMNY YEPES, Rodrigo. Bloque de constitucionalidade, derechos humanos y processo penal. Colombia: Consejo Superior de la Judicatura, 2008. 